\title{
Molecular detection of acute lymphoblastic leukaemia in boys with testicular relapse
}

Children's Cancer Institute Australia and the Department of Haematology and Oncology, Sydney Children's Hospital, Randwick, 2031, Sydney, Australia A Lal

E Kwan

M Al Mahr

L Zhou

D Ferrara

D O'Gorman Hughes

M Haber

M D Norris

G M Marshall

Department of Anatomical Pathology, Prince of Wales

Hospital, Randwick, Sydney, Australia V Tobias

Correspondence to: Dr Marshall.

Accepted for publication 11 June 1998

\begin{abstract}
A Lal, E Kwan, M Al Mahr, L Zhou, D Ferrara, V Tobias, D O'Gorman Hughes,
\end{abstract} M Haber, M D Norris, G M Marshall

\begin{abstract}
Aims-To determine the role of polymerase chain reaction (PCR) based minimal residual disease (MRD) detection of leukaemia specific DNA in testicular relapse in childhood acute lymphoblastic leukaemia.

Methods-DNA was obtained from archival testicular and bone marrow samples from boys with acute lymphoblastic leukaemia who relapsed in the testes. Overlapping $\mathrm{DJ}_{\mathrm{H}}$ clone specific primers derived from clonal immunoglobulin heavy chain (IgH) gene rearrangement in each case were used to analyse testicular or bone marrow DNA.

Results-Histologically normal end of treatment testicular biopsies in the five patients in longterm remission were all MRD negative, but MRD positive in three of six boys with subsequent testicular relapse. Histologically normal bone marrow samples taken at the end of treatment were MRD negative in five of seven cases, but MRD positive in all cases at the time of isolated testicular relapse. Three boys with unilateral testicular relapse underwent unilateral orchidectomy, rather than bilateral testicular irradiation, as part of their treatment. Two of these boys were MRD positive in the histologically uninvolved testes, and both had subsequent relapses either in the testes or the bone marrow, while the MRD negative patient has not had a testicular relapse.

Conclusions-The presence of MRD in testicular tissue can be assayed with a PCR based method to detect clone specific antigen receptor gene rearrangements. In this setting, PCR is more sensitive than conventional testicular histology for predicting clinical outcomes. MRD assays might be useful in the management of boys at the time of isolated testicular relapse, to confirm the presence of unilateral testicular disease.

(F Clin Pathol: Mol Pathol 1998;51:277-281)
\end{abstract}

Keywords: polymerase chain reaction; antigen receptor gene rearrangements; testicular leukaemia

Increasingly intensive chemotherapy regimens have seen significant improvements in the survival rates of children diagnosed with acute lymphoblastic leukaemia (ALL), and a reduction in the incidence of testicular relapse as a cause of treatment failure in boys with this disease.${ }^{1-3}$ Nonetheless, boys with ALL who are cured after a testicular relapse still face substantial longterm side effects of treatment as a result of bilateral testicular irradiation, which is administered in most centres as part of the treatment programme. ${ }^{45}$

Attempts to improve the cure rate of boys with ALL by presymptomatic testicular biopsy at the end of chemotherapy were unsuccessful for several reasons. ${ }^{167} \mathrm{~A}$ proportion of patients with histologically negative biopsies relapsed subsequently. ${ }^{6}$ In many cases, the biopsies were difficult to interpret because of the presence of "suspicious" cells that could not be classified definitely as malignant or benign. ${ }^{8}$ Most importantly, early detection and treatment of occult testicular relapse had no effect on longterm survival. ${ }^{16}$ In the past, studies aimed at improving the detection of testicular minimal residual disease (MRD) have included immunostaining for detection of lymphoblasts. In one study, which used immunodetection of terminal deoxynucleotidyl transferase (TdT) positive cells in testicular biopsy specimens, ${ }^{8}$ immunological and histological findings were discordant in four of 39 samples. Two patients with abnormal histology but normal immunostaining remained well on follow up (one after further treatment). The two cases with normal histology but weak TdT positivity also remained well with no further treatment. Therefore, the examination of testicular biopsy samples for TdT did not improve the precision of early diagnosis of testicular relapse. More sensitive methods of detecting ALL cells in testicular tissue might be more effective in predicting clinical outcome.

MRD studies using the polymerase chain reaction (PCR) have demonstrated low level genetic evidence of persistent leukaemia in many children with ALL during clinical remission. ${ }^{910}$ Strategies using PCR primers designed to detect clone specific, antigen receptor gene rearrangements in remission bone marrow samples are highly specific and sensitive (range, $10^{-3}$ to $10^{-6}$ ). In this retrospective study of archival testicular and bone marrow samples we compared conventional histology and PCR based MRD testing for predicting subsequent clinical outcomes.

\section{Patients and methods}

The study group comprised seven boys with ALL diagnosed between 1978 and 1993, who developed a testicular relapse after completion of treatment (table 1). Five boys with ALL in longterm first remission, who had presymptomatic end of treatment testicular biopsies, were selected as negative controls. At the time of testicular relapse, tissue from both testes from all seven patients was examined by light microscopy. Leukaemic infiltration was present in 
Table 1 Treatment and clinical characteristics of the testicular relapse patients

\begin{tabular}{|c|c|c|c|c|c|c|}
\hline Case & $\begin{array}{l}\text { WCC at } \\
\text { diagnosis }\end{array}$ & $\begin{array}{l}\text { Age at } \\
\text { diagnosis } \\
\text { (years) }\end{array}$ & Initial chemotherapy* & $\begin{array}{l}\text { Initial } \\
\text { treatment } \\
\text { (years) }\end{array}$ & $\begin{array}{l}\text { Time to relapse } \\
\text { Site of relapse }\end{array}$ & Treatment after relapse: duration ${ }^{*}$ \\
\hline 1 & $4.3 \times 10^{9} / 1$ & 3.5 & $\mathrm{VSM} / \mathrm{CP} / \mathrm{PCM}$, & 3 & $\begin{array}{l}0 \text { mo: } R \text { testis } \\
24 \text { mo: } L \text { testis }\end{array}$ & $\begin{array}{l}\text { Orchidectomy; MVPCSAD: } 24 \text { mo } \\
\text { TXRT; TSA: } 12 \text { mo }\end{array}$ \\
\hline 2 & $7.4 \times 10^{9} / 1$ & 2.5 & VDLS/CVA/VMP & 2 & $\begin{array}{l}14 \text { mo: testes, } \\
\text { BM }\end{array}$ & TXRT; AlloBMT \\
\hline 3 & $15.4 \times 10^{9} / 1$ & 8.0 & VDLS/CVA/VMP & 2 & $\begin{array}{l}7 \mathrm{mo}: \mathrm{BM} \\
26 \text { mo: } \mathrm{R} \text { testis }\end{array}$ & $\begin{array}{l}\text { AlloBMT } \\
\text { TXRT; MVPCSAD: } 24 \text { mo }\end{array}$ \\
\hline 4 & $9.6 \times 10^{9} / 1$ & 3.5 & VDLS/CPA/VMP & 2.5 & $\begin{array}{l}17 \text { mo: } R \text { testis } \\
26 \text { mo: } \mathrm{BM}\end{array}$ & $\begin{array}{l}\text { Orchidectomy; MVPCSAD: } 9 \text { mo } \\
\text { AlloBMT }\end{array}$ \\
\hline 5 & $7.8 \times 10^{9} / 1$ & 2.0 & VDLS/PM & 2.5 & $\begin{array}{l}16 \text { mo: } R \text { testis } \\
42 \text { mo: CNS }\end{array}$ & $\begin{array}{l}\text { Orchidectomy, DVASMPC: } 15 \mathrm{mo} \\
\text { CXRT; ATM/LMP/MGVI : } 24 \mathrm{mo}\end{array}$ \\
\hline 6 & $351 \times 10^{9} / 1$ & 0.9 & VDLS/ACPM/VSMP & 2.5 & 30 mo: $\mathrm{R}$ testis & TXRT, VDLS/CVA/LMP/VMP: $24 \mathrm{mo}$ \\
\hline 7 & $48 \times 10^{9} / 1$ & 4.5 & VDLS/ACV/LPM/VPM & 2 & $\begin{array}{l}5 \text { mo: } \mathrm{BM} \\
18 \mathrm{mo}: \text { both } \\
\text { testes }\end{array}$ & $\begin{array}{l}\text { AlloBMT } \\
\text { TXRT; VDS/MPXS/VC/MP: } 24 \mathrm{mo}\end{array}$ \\
\hline
\end{tabular}

${ }^{\star}$ Different phases of treatment are separated by $/ .{ }^{\star \star}$ Time from end of initial treatment to relapse.

A, cytarabine; AlloBMT, allogeneic bone marrow transplant; BM, bone marrow; C, cyclophosphamide; CXRT, cranial radiotherapy; $\mathrm{D}$, daunorubicin; G, 6-thioguanine; I, vindesine; L, asparaginase; M, methotrexate; mo, months; P, mercaptopurine; R/L, right/left; S, prednisolone; T, VM-26; TXRT, testicular radiotherapy; V, vincristine; WCC, total leucocyte count; X, doxorubicin.

both testes in three patients and limited to one testis in four cases.

TREATMENT AND OUTCOME

The initial chemotherapy was in accordance with the ongoing institutional ALL protocols at the time of diagnosis (table 1), as detailed elsewhere. ${ }^{11} 12$ Treatment following relapse always included local treatment and systemic reinduction followed by rotating courses of non-intensive chemotherapy for a further period of two years. Four patients (cases 2, 3, 4, and 7) received an allogeneic, fully HLA matched, sibling donor bone marrow transplant as part of their treatment for bone marrow relapse.

Local treatment in the three patients with bilateral testicular involvement, and one patient with unilateral testicular involvement (case 6) was irradiation (24 Gy) of both testes. Three patients with leukaemic infiltration limited to one testis underwent orchidectomy without radiotherapy to the uninvolved testis.

No patient in this series has died of disease, with the sole death attributed to lung disease 18 months following allogeneic bone marrow transplant (case 4). Four patients (cases 1, 2, 3, and 5) are longterm survivors after stopping chemotherapy (range, 3.5-13 years) and two patients (cases 6 and 7 ) are still on treatment.

\section{DNA PREPARATION}

Genomic DNA was recovered from paraffin wax embedded tissues and bone marrow slides, using the method of Grunewald et al. ${ }^{13}$ Genomic DNA was isolated from normal bone marrow specimens following Ficoll-Hypaque gradient centrifugation, and also from normal human placenta using standard techniques, as reported previously. ${ }^{1415}$

\section{ANTIGEN RECEPTOR GENE REARRANGEMENT ANALYSIS}

DNA from the testicular relapse tissue was analysed using consensus immunoglobulin heavy $(\operatorname{IgH})$ chain $\mathrm{V}_{\mathrm{H}}$ and $\mathrm{J}_{\mathrm{H}}$ PCR primers directed to the CDR III region of the IgH gene, as described previously. ${ }^{14} \mathrm{~A}$ patient specific, clonal IgH gene rearrangement was detected in all 12 cases. Clonal IgH gene PCR products

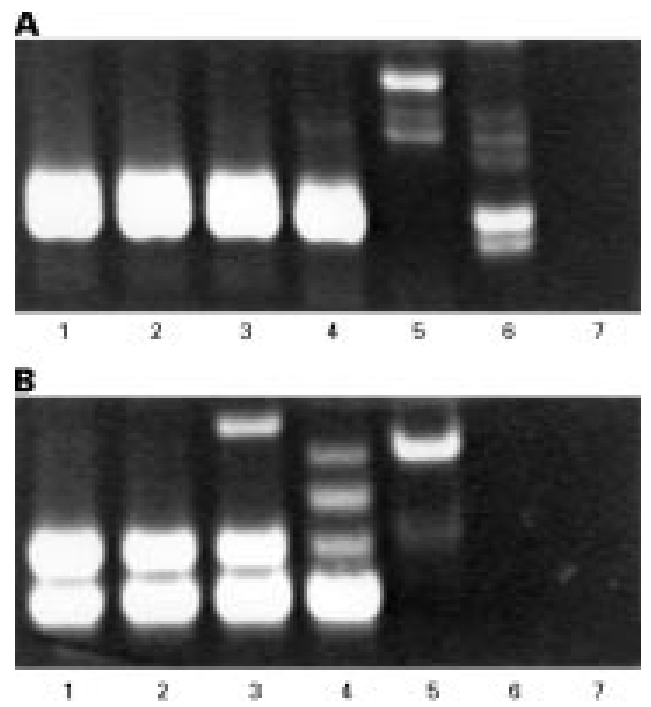

Figure 1 Detection of leukaemic DNA in testicular tissue with PCR using clone specific primers. Serial dilution of DNA from relapse testis in normal testicular DNA is shown for two patients. (A) Case 4: lanes 1-6, serial dilutions from $10^{-1} 1$ to $10^{-6}$; lane 7 , negative (water) control. Sensitivity of detection is 1/10 000. The faint band in lane 6 probably represents amplification of a polyclonal IgH sequence. (B) Case 2: lanes 1-5, serial dilutions from $10^{-2}$ to $10^{-6}$; lanes 6 and 7 , negative (water) controls. Sensitivity of detection is 1/100000.

were sequenced, and overlapping $\mathrm{DJ}_{\mathrm{H}}$ clone specific primers were synthesised for each patient. These clone specific PCR primers were then used to analyse testicular or bone marrow DNA in a two step, semi-nested PCR reaction, using the forward consensus $\mathrm{V}_{\mathrm{H}}$ region primer and the reverse clone specific $\mathrm{DJ}_{\mathrm{H}}$ primers, as described previously. ${ }^{15}$ The specificity of clonal IgH PCR primers was confirmed by performing PCR analysis on DNA from normal human bone marrow samples. The patient specific $\operatorname{IgH}$ PCR primers were also tested for sensitivity following serial dilution of DNA from the patient's relapse testis in normal testicular DNA. The limit of sensitivity ranged from $10^{-3}$ to $10^{-5}$ (fig 1).

\section{Results}

COMPARISON OF HISTOLOGY AND MRD ANALYSIS OF TESTICULAR TISSUE BEFORE RELAPSE

Initially, we analysed testicular biopsy and bone marrow samples taken before clinical 


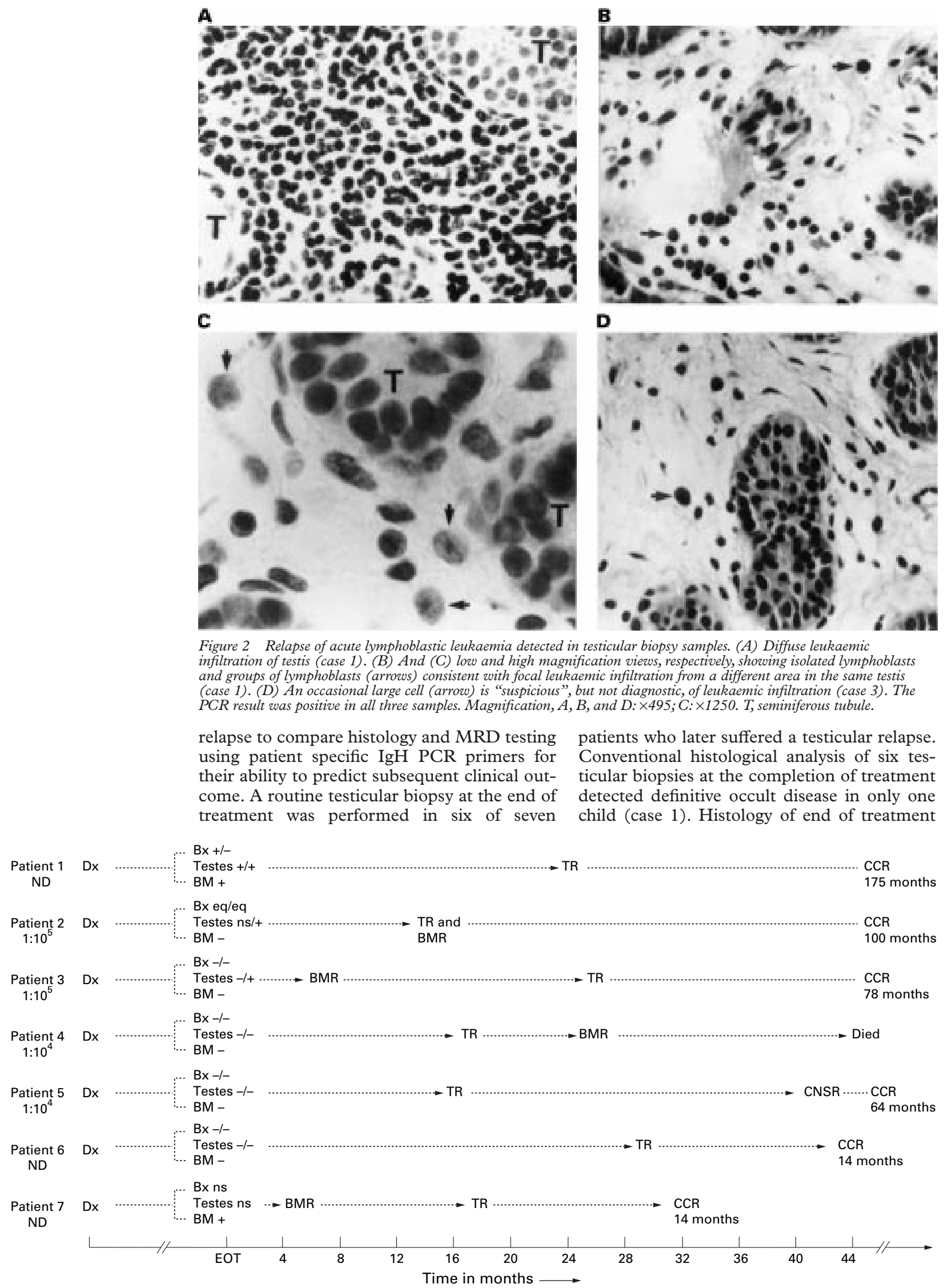

Figure 3 Results of end of treatment testicular and bone marrow samples and subsequent outcome. The sensitivity of detection of MRD in testicular tissue is mentioned under each patient (ND, not determined). Patient 7 did not have an end of treatment testicular biopsy. Arrowheads indicate actual time intervals; BM, PCR result on bone marrow; BMR, bone marrow relapse; Bx, histology result on left/right testicular biopsies; CCR, continuous complete remission; CNSR, central nervous system relapse; Dx, diagnosis; EOT, end of primary chemotherapy; eq, equivocal (not possible to exclude with certainty the presence of lymphoblasts in testicular biopsy); ns, no sample; Testes, PCR result on left/right testis; TR, testicular relapse. 
testicular biopsies was classified as normal in both testes in three cases, equivocal in two cases, and normal in one testis, but abnormal on the other side in case 1 (fig 2). Five patients in longterm remission, who underwent routine end of treatment testicular biopsies, were selected as negative controls. In all five cases, the testicular tissue was normal on histology and negative on MRD testing (data not shown).

The results of histology and PCR on end of treatment testicular tissue were then compared in six of the seven patients with subsequent testicular relapse (fig 3 ). This group comprised five end of treatment biopsies from patients with subsequent testicular relapse, and one patient who was treated with chemotherapy and orchidectomy, instead of bilateral testicular irradiation, and was thus at risk of later testicular relapse. PCR detected the presence of MRD in testicular tissue in three of these six patients. The interval from biopsy to testicular relapse did not differ significantly among patients with or without testicular MRD at the end of treatment. MRD testing of testicular tissue correctly predicted the subsequent clinical outcome in eight of 11 patients, compared with six of 11 for histological analyses.

ANALYSIS OF BONE MARROW SAMPLES FOR MRD FROM BOYS WITH TESTICULAR RELAPSE

At the end of treatment, bone marrow was normal on microscopic examination in all seven patients with testicular relapse. No evidence of MRD was found by PCR in five patients (fig 3); however, two of these five MRD negative patients suffered bone marrow relapse seven and 14 months after cessation of treatment. MRD was detected in the bone marrow sample at the end of treatment in one child with simultaneous histological evidence of disease in the testis (case 1), and another child who developed bone marrow relapse five months later. The absence of MRD in the end of treatment bone marrow sample did not predict freedom from a subsequent marrow or testicular relapse.

At the time of testicular relapse, bone marrow was normal on microscopic examination in six patients (isolated testicular relapse) and abnormal in one patient (combined bone marrow and testicular relapse). The presence of MRD in the bone marrow was demonstrated in all six patients at the time of isolated testicular relapse (table 2). This indicated the presence of systemic disease in every child with a clinically isolated testicular relapse.
Table 2 Bone marrow analyses at testicular relapse

\begin{tabular}{lll}
\hline Case & Histology & PCR \\
\hline 1 & - & + \\
2 & + & + \\
3 & - & + \\
4 & - & + \\
5 & - & + \\
6 & - & + \\
7 & - & +
\end{tabular}

PCR, polymerase chain reaction.
MRD negative patient (case 5) has remained free of testicular disease despite not receiving testicular irradiation.

For six of the seven patients who suffered a testicular relapse, the clonal IgH sequence present at relapse was identical to the sequence in the initial diagnosis bone marrow. However, one patient (case 6) demonstrated clonal evolution of the $\operatorname{IgH}$ sequence in testicular relapse tissue. The clonal IgH rearrangement present in the testicular relapse tissue retained the $\mathrm{DJ}_{\mathrm{H}}$ region, but differed in the $\mathrm{VD}_{\mathrm{H}}$ sequence. The initial diagnosis $\operatorname{IgH}$ sequence was not present in the testicular relapse tissue. However, the relapse $\operatorname{IgH}$ sequence was evident in the histologically normal marrow at the time of testicular relapse, but not in the initial diagnosis marrow. These findings suggest that the process of clonal evolution had occurred in the testes, with subsequent seeding of the bone marrow.

\section{Discussion}

We found PCR to be highly specific and more sensitive than conventional testicular histology in the detection of MRD in testicular tissue. There were no false positive results among the five patients in longterm remission. MRD was testicular samples that had appeared normal or equivocal on microscopic examination in three of six boys with subsequent testicular relapse. In addition, PCR was helpful in confirming the presence or absence of leukaemia in histologically uninvolved testes from boys with unilateral testicular relapse. Although MRD was not detected in bone marrow samples in most had demonstrable MRD in the bone marrow at testicular relapse.

False negative results for MRD were obtained in the end of treatment testicular biopsy samples in three patients who later relapsed in evolution of the leukaemic clone between the diagnosis and relapse samples, a phenomenon known to occur in $20-30 \%$ of patients with ALL suffering a bone marrow relapse. ${ }^{14}{ }^{16}$ In the other two patients, the false negative result is analogous to the occurrence of a bone marrow relapse in the absence of MRD in the bone marrow at completion of treatment, ${ }^{17}$ and could have arisen if the quantity of leukaemic cells infiltrating the testes was below the sensitivity of detection of the test. It is also possible that the leukaemic infiltration was confined to specific regions of the testis (fig 2) and, therefore, was missed in the small tissue sample used to extract DNA. A final possibility, that the spread of leukaemia to the testes occurred after the end of treatment from residual disease elsewhere in the body, appears less likely. This is because two of these patients (cases 5 and 6) did not experience a bone marrow relapse and, in the third patient (case 4), bone marrow relapse followed testicular relapse by some nine months.

Our data suggest that the testes act as a sanctuary site in boys with ALL. Two patients (cases 2 and 3 ) in our study, who went on to demonstrated in routine end of treatment patients at the end of treatment, every patient the testes. In one of the three cases, there was testing. All three patients have relapsed subsequently: case 1 in the testes, case 4 in the bone marrow, and case 5 in the central nervous system, at 24,9 , and 26 months, respectively. The
MOLLOWING RELAPSE

Following testicular relapse, unilateral orchidctomy, instead of bilateral testicular ira histology showed leukaemic infiltration to be limited to one testis. Two of these histologically 
develop testicular relapse, demonstrated residual leukaemia in the testes, but not in the bone marrow, at completion of treatment. A third patient (case 6) with clonal evolution at testicular relapse had no evidence of the new DNA sequence either in the initial diagnosis bone marrow, or the end of treatment samples, whereas the bone marrow sample at testicular relapse tested positive for the new sequence. The presence of overt disease in the testes suggests that the process of clonal evolution occurred in the testes and later spread to the bone marrow.

The results demonstrate clearly that the absence of MRD in the bone marrow at completion of treatment does not rule out a subsequent testicular relapse. Of the two patients with evidence of $\mathrm{MRD}$, one had histological evidence of disease in the testis and the other developed a bone marrow relapse six months later. On the other hand, the presence of MRD in concurrent bone marrow samples obtained at isolated testicular relapse in all six cases confirmed previous reports demonstrating that extramedullary relapse in childhood ALL is always a systemic disease. ${ }^{18-20}$

As expected, ${ }^{47}$ the outcome following testicular relapse was excellent in this series. The standard approach to local treatment in testicular relapse remains radiotherapy to both testes, which induces infertility and often requires these boys to be treated with testosterone for initiation or continuation of puberty. ${ }^{45}$ A previous study has shown that only a minority of patients with unilateral testicular disease on histology will relapse in the contralateral testis if the local treatment is limited to the affected side. ${ }^{21}$ We have shown that with the use of PCR it is possible to exclude the presence of occult disease in the histologically normal testis at the time of relapse (three of seven boys in our study). The feasibility of restricting local treatment to the affected testis, guided by PCR results, needs to be investigated to reduce longterm toxicity. However, there are insufficient data to advocate the routine use of PCR to predict testicular relapse on samples obtained from asymptomatic patients.

In summary, we have demonstrated the feasibility of PCR detection of MRD in testicular tissue. In this setting, PCR is highly specific and more sensitive than histology. Further studies are needed to prove that PCR can accurately identify unilateral disease in boys with ALL who suffer a testicular relapse, which might make it possible to restrict local treatment to the affected side.

This work was supported by grants from the National Health and Medical Research Council of Australia, the New South Wales State Cancer Council, the Sydney Children's Hospital Foundation, and the Children's Cancer Institute Australia.
1 Miller DR, Leikin SL, Albo VC, et al. The prognostic value of testicular biopsy in childhood acute lymphoblastic leukemia: a report from the childrens cancer study group. $\mathcal{F}$ Clin Oncol 1990;8:57-66.

2 Reiter A, Schrappe M, Ludwig WD, et al. Chemotherapy in 998 unselected childhood acute lymphoblastic leukemia patients. Results and conclusions of the ALL-BFM 86. Blood 1994;84:3122-33.

3 Chessells JM, Bailey C, Richards SM. Intensification of treatment and survival in all children with lymphoblastic leukaemia: results of UK Medical Research Council trial UKALL X. Medical Research Council working party on childhood leukaemia. Lancet 1995;345:143-8.

4 Grundy RG, Leiper AD, Stanhope R, et al. Survival and endocrine outcome after testicular relapse in acute lymphoblastic leukaemia. Arch Dis Child 1997;76:190-6.

5 Blatt J, Sherins RJ, Niebrugge D, et al. Leydig cell function in boys following treatment for testicular relapse of acute lymphoblastic leukemia. F Clin Oncol 1985;3:1227-31.

6 Nachman J, Palmer NF, Sather HN, et al. Open-wedge testicular biopsy in childhood acute lymphoblastic leukemia after two years of maintenance therapy: diagnostic accuracy and influence on outcome-a report from children's cancer study group. Blood 1990;75:1051-5.

7 Wofford MM, Smith SD, Shuster JJ, et al. Treatment of occult or late overt testicular relapse in children with acute lymphoblastic leukemia: a pediatric oncology group study. f Clin Oncol 1992;10:624-30.

8 Chessells JM, Pincott JR, Daniels-Lake W. Terminal transferase positive cells in testicular biopsy specimens from boys with acute lymphoblastic leukaemia. 7 Clin Pathol 1986;39:1236-40.

9 Cave H, Guidal C, Rohrlich P, et al. Prospective monitoring and quantitation of residual blasts in childhood acute lymphoblastic leukaemia by polymerase chain reaction study of d and g T-cell receptor genes. Blood 1994;83:1892902 .

10 Roberts WM, Estrov Z, Ouspenskaia MV, et al. Measurement of minimal residual leukemia during remission in childhood acute lymphoblastic leukaemia. $N$ Engl f Med 1997;336:317-23.

11 Brisco MJ, Condon J, Hughes E, et al. Outcome prediction in childhood acute lymphoblastic leukaemia by molecular quantification of residual disease at the end of induction. Lancet 1994;343:196-200.

12 Carpenter PA, Marshall GM, Giri N, et al. Allogeneic bone marrow transplantation for children with acute lymphoblastic leukemia conditioned with busulfan, cyclophosphamide and melphalan. Bone Marrow Transplant 1996;18: 489-94.

13 Grunewald K, Lyons J, Hansen-Hagge TE, et al. Molecular genetic analysis of DNA obtained from fixed, air dried or paraffin embedded sources. Ann Hematol 1991,62:108-14.

14 Marshall GM, Kwan E, Haber M, et al. Characterisation of clonal immunoglobulin heavy chain and T cell receptor $\gamma$ gene rearrangements during progression of childhood acute lymphoblastic leukemia. Leukemia 1995;9:1847-50.

15 Norris MD, Kwan E, Haber M, et al. Detection of evolving immunoglobulin heavy-chain gene rearrangements in acute lymphoblastic leukemia: a PCR-based assay employing overlapping DJH primers. Leukemia 1995;9:1779-82.

16 Steward CG, Goulden NJ, Katz F, et al. A polymerase chain reaction study of the stability of Ig heavy-chain and T-cell receptor $\gamma$ gene rearrangements between presentation and relapse of childhood B-lineage acute lymphoblastic leukaemia. Blood 1994;83:1355-62.

17 Ito Y, Wasserman R, Galili N, et al. Molecular residual disease status at the end of chemotherapy fails to predict subsequent relapse in children with B-lineage acute lymphoblastic leukemia. f Clin Oncol 1993;11:546-53.

18 Goulden N, Langlands K, Steward C, et al. PCR assessment of bone marrow status in "isolated" extramedullary relapse of childhood B-precursor acute lymphoblastic leukaemia. Br f Haematol 1994;87:282-5.

19 Neale GA, Pui CH, Mahmoud HH, et al. Molecular evidence for minimal residual bone marrow disease in children with "isolated" extra-medullary relapse of T-cell acute dren with "isolated" extra-medullary relapse of T-cell

20 O'Reilly J, Meyer B, Baker D, et al. Correlation of bone marrow minimal residual disease and apparent isolated extramedullary relapse in childhood acute lymphoblastic leukaemia. Leukemia 1995;9:624-7.

21 Bowman WP, Aur RJ, Hustu HO, et al. Isolated testicular relapse in acute lymphocytic leukemia of childhood: categories and influence on survival. $f$ Clin Oncol 1984;2:24-9. 